Check for updates

Cite this: RSC Adv., 2017, 7, 19960
Received 5th February 2017 Accepted 13th March 2017 DOI: $10.1039 / \mathrm{c} 7 \mathrm{ra01485f}$ rsc.li/rsc-advances

\section{Rice flour-based nanostructures via a water-based system: transformation from powder to electrospun nanofibers under hydrogen-bonding induced viscosity, crystallinity and improved mechanical property $\dagger$}

\author{
Sarekha Woranuch, Autchara Pangon, Kantapat Puagsuntia, Nakarin Subjalearndee \\ and Varol Intasanta*
}

Rice flour is a naturally abundant and renewable biodegradable and biocompatible material. Nevertheless, fabrication of rice flour-based functional nanostructures has been challenging due to the difficulties in finetuning solution parameters. The present work shows a successful synthesis of rice-flour based nanofibers containing PVA by simply allowing rice flour and PVA to solubilize in alkaline conditions prior to electrospinning. Rice flour/PVA blend nanofibers at the rice flour weight content of $25 \%$ led to an optimal condition with reinforced hydrogen bonding between the two polymers. The interaction induced good processability and fiber formation with well-defined morphology. In addition, rice flour functioning as a nucleating agent promoted the crystallization of small PVA crystals resulting in an improvement of tensile strength and Young's modulus with respect to PVA nanofibers. This is for the first time showing not only the transformation of rice flour via a water-based system into mechanically robust nanofibers, but also the role of rice flour in inducing crystalline phase in semi-crystalline polymers in blends. The finding is important to bring in unprecedented practical applications for rice flour such as disposable nanofilters, tissue engineering scaffolds, wound dressings, etc.

\section{Introduction}

Rice starch is a biopolymer obtained from rice flour via an alkaline steeping method. ${ }^{1}$ Starch represents a unique class of polysaccharides due to its rich variety of amylose-amylopectin combinations. While amylose is a linear chain and amorphous part of starch granule, amylopectin constitutes a branched and crystalline component. The interplay between these two key components in a vast degree of amylose fraction lead to various types of rice showing different physical structure and mechanical performance. ${ }^{2,3}$ Starches have been of high demand due to their non-toxicity, biodegradability, biocompatibility, and ability to form films, membranes, gels, and fibers. ${ }^{4-6}$

Recently, nanofibers have received much attention due to their applications in many areas such as high-performance filter media, sensors, medicine and medical textile materials. ${ }^{7,8}$ Various methods have been developed to fabricate

Nano Functional Textile Laboratory, National Nanotechnology Center, National Science and Technology Development Agency, 111 Phahonyothin Road, Klong Nueng, Klong Luang, Pathumthani, 12120, Thailand. E-mail: varol@nanotec.or.th; Fax: +66 2564 6981; Tel: +66 25647100 ext. 6580

$\dagger$ Electronic supplementary information (ESI) available. See DOI: 10.1039/c7ra01485f nanomaterials, e.g. drawing, phase separation, self-assembly, template synthesis and electrospinning. ${ }^{9-12}$ Compared with other techniques, electrospinning could be applicable for a wide range of polymers, capable of controlling fiber morphology with potential for scaling up production.

Only a few works have investigated starch-based fibers prepared through electrospinning technology. Kong and Ziegler $^{13}$ studied the preparation of pure corn starch fibers by electro-wet-spinning. The result showed that starch fibers had diameters in the order of microns and crystallinity of the fibers was increased after spinning. However, this method involved a multi-step process including organic solvent elimination. Another related work studied the fabrication of glutinous rice starch nanofibers by electrospinning. The authors found that glutinous rice starch nanofibers exhibited high porosity, flake multi-layers and high swelling power. $^{\mathbf{1 4}}$ In addition, some previous studies indicated that pure starch material exhibited poor processability and properties (e.g., weak mechanical properties, poor long-term stability) as compared with synthetic polymers. As a solution, flour was often blended with synthetic biodegradable polymers such as polyvinyl alcohol (PVA), polycaprolactone (PCL) and polylactide (PLA). ${ }^{15-17}$

Among the biodegradable polymers, PVA has high interest due to its processability, biocompatibility, nontoxicity and 
solubility in water, which makes it similar to starch. PVA also contains hydroxyl groups, identical to starch. However, the properties of PVA are highly dependent on the degree of hydrolysis $(\mathrm{DH})$. It was reported that PVA with $\mathrm{DH}$ between 87 and 89 exhibited low mechanical stability, ${ }^{18}$ which could be improved via blends e.g. combining PVA with starch to produce high strength biocomposite film. ${ }^{15}$ Therefore, the fabrication of bio-based nanofibers for future applications in disposable nanofiltrations and other environmentally friendly products is an interesting alternative to preserve its functional properties.

The objective of the present research was to fabricate rice starch-based functional nanofibers by overcoming the difficulties in fine-tuning solution parameters. Here, rice flour was selected to fabricate bio-based nanofibers because it could be simply obtained by physical grinding without any further purification process. As electropsinning of water-based rice flour solution was difficult, PVA was introduced to facilitate both solution stability and fiber formation. The influence of rice flour content on viscosity, morphology, chemical structure, crystallinity, thermal characteristics and mechanical property of rice flour-based nanofibers were investigated.

\section{Materials and methods}

\subsection{Materials}

Rice flour (Amylose content of 22.67\%) was supplied by Bureau of Rice Research and Development, Thailand. Polyvinyl alcohol (PVA, $M_{\mathrm{w}} \sim 205000 \mathrm{~g} \mathrm{~mol}^{-1}$, Sigma-Aldrich) and sodium hydroxide ( $\mathrm{NaOH}$, Sigma-Aldrich) were of analytical grade and used as received. Deionized water was used in all experiments.

\subsection{Preparation of rice flour/PVA solution}

PVA solution of $8 \% \mathrm{w} / \mathrm{w}$ was prepared with DI water at $95{ }^{\circ} \mathrm{C}$ under magnetic stirring for $2 \mathrm{~h}$. In another beaker, $8 \% \mathrm{w} / \mathrm{w}$ of rice flour solution was prepared with a solution of $0.2 \mathrm{mM}$ of sodium hydroxide. Then, the two solutions were mixed followed by magnetic stirring at room temperature for 15 minutes at the weight ratio of rice flour solution to PVA solution of $0: 100$, $12.5: 87.5,25: 75$ and $37.5: 62.5$. As a result, the solid contents of rice flour in nanofibers were varied for $0 \%, 12.5 \%, 25.0 \%$ and $37.5 \% \mathrm{w} / \mathrm{w}$, respectively.

\subsection{Fabrication of nanofibers by electrospinning}

Electrospinning was carried out using Nanospider technology (Nanospider laboratory machine NS LAB 500S, Elmarco s.r.o). The spinning solution $(25 \mathrm{~mL})$ was poured into the Nanospider's $50 \mathrm{~mL}$ semi cylindrical reservoir, equipped with wire electrodes connected to a high-voltage supply. During the process, the electrode was rotated at $8 \mathrm{rpm}$. The distance between the rotating wire electrode and the ground electrode was $18 \mathrm{~cm}$. In this work, the applied voltage was set at $65 \mathrm{kV}$.

\subsection{Characterization}

Viscosity of the solutions was investigated using a DV-IIV cone ultra programmable rheometer equipped with CPA-40Z cone and plate geometry spindle at $25{ }^{\circ} \mathrm{C}$ (average of 10 measurements; Brookfield Engineering Laboratories Inc., USA). Morphological analyses were done using Scanning Electron Microscopy (SEM) Hitachi E-1010 (Hitachi High-Technologies Corp., Japan). A sample was fixed on a specimen stub with carbon adhesive tape and sputter-coated with a thin layer of gold. Finally, SEM micrographs were collected at an accelerating voltage of $20 \mathrm{kV}$ and working distance of $5 \mathrm{~mm}$. FTIR spectra were obtained with a Nicolet 6700 (Thermo Scientific, Inc., United States) using 128 scans at a resolution of $2 \mathrm{~cm}^{-1}$ over a wavenumber range of $500-4000 \mathrm{~cm}^{-1}$. X-ray diffraction (XRD) patterns were recorded by a Bruker D8 Advance X-ray diffractometer (Germany) over a $2 \theta$ range from $5^{\circ}$ to $60^{\circ}$ with a scan rate of $0.04^{\circ} \mathrm{min}^{-1}$. The degree of crystallinity of the sample can be determined from XRD pattern. The degree of crystallinity $\left(X_{\mathrm{c}}\right)$ was calculated from eqn (1):

$$
X_{\mathrm{c}}(\%)=\left(A_{\mathrm{c}} /\left[A_{\mathrm{c}}+A_{\mathrm{a}}\right]\right) \times 100
$$

where $A_{\mathrm{c}}$ is the area under the peaks representing the total crystalline region and $A_{\mathrm{a}}$ is the area under the peaks representing the total amorphous region.

The average crystallite size was calculated using the following well-known Scherrer eqn (2):

$$
\text { Crystallite size }(\mathrm{nm})=k \lambda / \beta \cos \theta
$$

where $k$ is Scherrer constant (0.89), $\lambda$ is wavelength of $\mathrm{Cu} \mathrm{K \alpha}$ radiation $(0.154 \mathrm{~nm}), \beta$ is the peak width of the diffraction peak profile at the half maximum height (FWHM) and $\theta$ is the Bragg angle. ${ }^{19}$

Thermogravimetric analysis (TGA) was performed using a TGA/DSC 1 STARe (Mettler-Toledo, Switzerland) under nitrogen atmosphere with a flow rate of $50 \mathrm{~mL} \mathrm{~min}{ }^{-1}$. Each sample $(5 \mathrm{mg})$ was placed in a crucible and then heated from $30{ }^{\circ} \mathrm{C}$ to $600{ }^{\circ} \mathrm{C}$ at a heating rate of $10^{\circ} \mathrm{C} \mathrm{min}{ }^{-1}$. Differential scanning calorimetry (DSC) analysis was performed with a Mettler-Toledo DSC 822e. A sample (5 mg each) was then packed in a DSC aluminum pan with a closed lid having a 1 mm-diameter hole at the center. The first heating scan was carried out from $-50{ }^{\circ} \mathrm{C}$ to $250{ }^{\circ} \mathrm{C}$ at a heating rate of $20{ }^{\circ} \mathrm{C}$ $\min ^{-1}$. The sample was then cooled to $-50{ }^{\circ} \mathrm{C}$ at a cooling rate of $20{ }^{\circ} \mathrm{C} \mathrm{min}{ }^{-1}$, held at $-50{ }^{\circ} \mathrm{C}$ for $5 \mathrm{~min}$, and reheated from $-50{ }^{\circ} \mathrm{C}$ to $250{ }^{\circ} \mathrm{C}$ at a heating rate of $20{ }^{\circ} \mathrm{C} \mathrm{min}{ }^{-1}$. A nitrogen

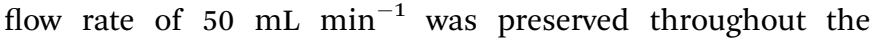
experiment.

\subsection{Tensile testing of nanofibers}

Mechanical properties of the samples were examined according to ASTM D882 standard test method, using an Instron Model 5566 testing machine (UK). A sample was cut into a rectangular shape $(5 \mathrm{~cm} \times 1 \mathrm{~cm})$ prior to testing. The test was performed using a load cell of $1 \mathrm{kN}$, a crosshead speed of $10 \mathrm{~mm} \mathrm{~min}^{-1}$ and a grip separation of $10 \mathrm{~mm}$. Five replicates were tested for each sample to obtain an average value. The film thickness was measured at five positions on the perimeter and at the center of the film by a digital caliper to obtain an average value. 


\section{Results and discussion}

\subsection{Viscosity of electrospinning solution}

Viscosity is an important factor for electrospinning as well as an indicator for macromolecule entanglements in solution. Fig. 1 illustrates the viscosity of rice flour solution, PVA solution and rice flour/PVA solutions at rice flour contents of $12.5 \% \mathrm{w} / \mathrm{w}, 25 \%$ $\mathrm{w} / \mathrm{w}$ and $37.5 \% \mathrm{w} / \mathrm{w}$. Blend solutions at the weight content of rice flour for $12.5 \% \mathrm{w} / \mathrm{w}$ and $25 \% \mathrm{w} / \mathrm{w}$ exhibited higher viscosity (273-340 cP) than PVA solution. The augmentation of PVA solution viscosity after adding rice flour might result from the interaction and entanglement between the two polymers. The decrease of viscosity when rice flour content was increased to $37.5 \% \mathrm{w} / \mathrm{w}$ might be explained by reduced chain entanglement among the polymer molecules due to phase separation between excessive rice flour solution and PVA solution. ${ }^{20}$

\subsection{Morphology of rice flour/PVA nanofibers}

The morphology of the obtained nanofibers was observed by a scanning electron microscopy (SEM), as shown in Fig. 2. It could be seen that electrospinning of pure rice four solution resulted in no fibers (Fig. 2a). For PVA solution, the resulting nanofibers exhibited physical uniformity with the mean diameter of $158 \pm 23 \mathrm{~nm}$ (Fig. 2b). Upon blending with PVA, the blend nanofibers at the weight content of rice flour of $12.5 \% \mathrm{w} /$ $\mathrm{w}$ and $25 \% \mathrm{w} / \mathrm{w}$ also showed continuous and uniform nanofibers with an average diameter of $156 \pm 31 \mathrm{~nm}$ and $151 \pm$ $36 \mathrm{~nm}$, respectively (Fig. 2c and d). The result indicated that PVA provided good spinnability which was consistent with a previous investigation on PVA/starch blends reported by Liu and $\mathrm{He}$ (2014). ${ }^{21}$ The improved quality was ascribed to the augmentation of solution viscosity due to enhanced polymer chain entanglement. However, rice flour/PVA nanofibers at even higher weight content of rice flour of $37.5 \% \mathrm{w} / \mathrm{w}$ gave nonuniform fibers with the mean diameter of $162 \pm 57 \mathrm{~nm}$ (Fig. 2e). This result was related to the above relatively lower viscosity (see Section 3.1.) possibly due to poor entanglement of polymer chains. It could be inferred that spinnability of rice

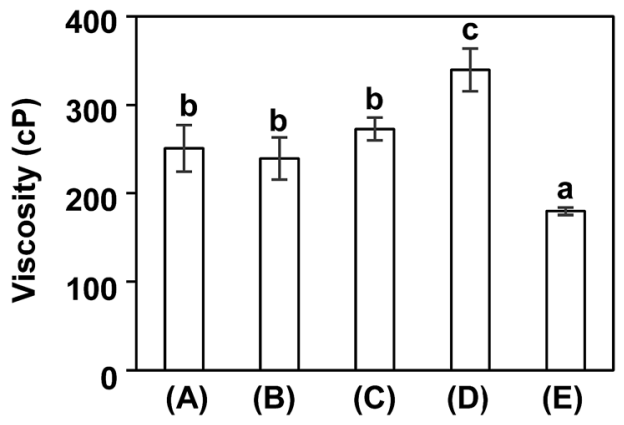

Fig. 1 Viscosity of $(A)$ rice flour solution (B) polyvinyl alcohol (PVA) solution; and $(c-e)$ rice flour/PVA solutions at different contents of rice flour for (C) $12.5 \% \mathrm{w} / \mathrm{w}$, (D) $25 \% \mathrm{w} / \mathrm{w}$ and (E) $37.5 \% \mathrm{w} / \mathrm{w}$. The data is reported as mean $\pm \mathrm{SD}, n=10$. The small cap letters indicate significant difference at $p<0.05$ (Duncan's new multiple range test).
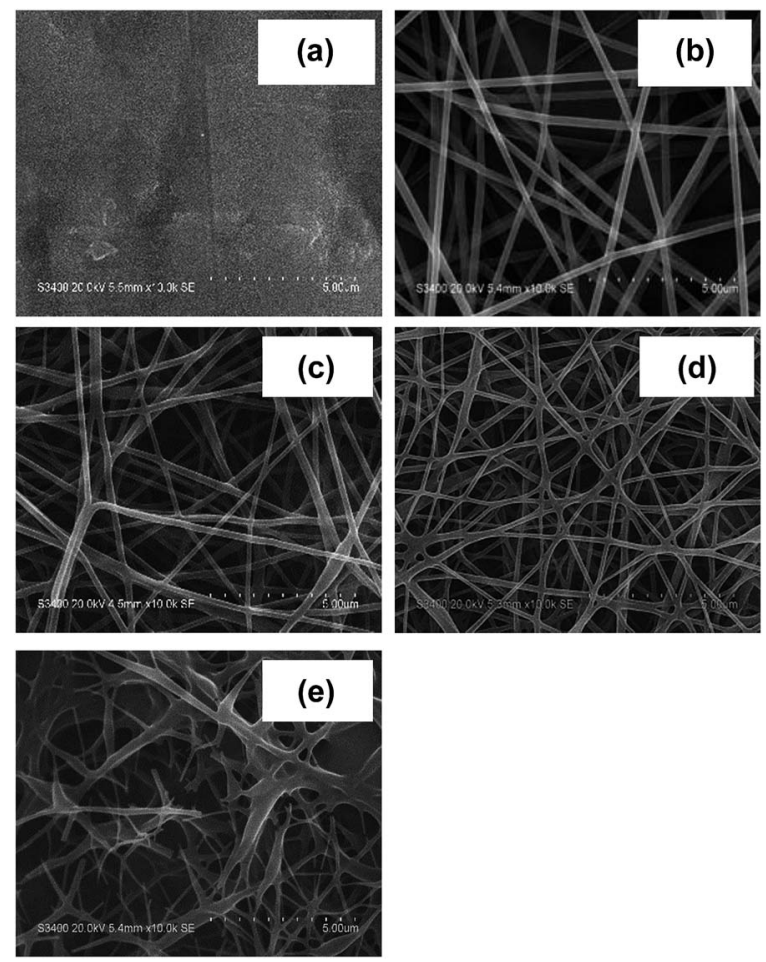

Fig. 2 SEM micrographs at $20 \mathrm{kV}$ of different membranes: (a) rice flour; (b) polyvinyl alcohol (PVA); and (c-e) rice flour/PVA membranes at different contents of rice flour for (c) $12.5 \% \mathrm{w} / \mathrm{w}$, (d) $25 \% \mathrm{w} / \mathrm{w}$ and (e) $37.5 \% \mathrm{w} / \mathrm{w}$.

flour-based nanofibers might be limited at rice flour content of $37.5 \% \mathrm{w} / \mathrm{w}$ owing to the low viscosity.

\subsection{Molecular interaction}

FITR spectroscopy was applied on the resulted nanofibers to investigate the chemical interactions between rice flour and PVA. In Fig. 3a, PVA nanofibers show characteristic peaks at $3295 \mathrm{~cm}^{-1}$ (OH stretching), $2911 \mathrm{~cm}^{-1}$ (C-H stretching), 1728 $\mathrm{cm}^{-1}$ and $1713 \mathrm{~cm}^{-1}(\mathrm{C}=\mathrm{O}$ stretching of acetate group), 1438 $\mathrm{cm}^{-1}$ (CH2 symmetric bending), $1090 \mathrm{~cm}^{-1}$ (C-O stretching of ether group) and $852 \mathrm{~cm}^{-1}$ (C-C bending). ${ }^{22}$ In Fig. $3 \mathrm{~b}$, rice flour possessed characteristic peaks at $3290 \mathrm{~cm}^{-1}(\mathrm{OH}), 2920 \mathrm{~cm}^{-1}$ (C-H stretching), $1640 \mathrm{~cm}^{-1}$ (OH bonding of water), $1002 \mathrm{~cm}^{-1}$ and $998 \mathrm{~cm}^{-1}$ (C-O stretching). ${ }^{23,24}$ It was clearly observed that rice flour/PVA nanofibers showed both characteristic peaks of rice flour and PVA, i.e. $\mathrm{C}-\mathrm{O}$ stretching of glycosidic linkage at $1002 \mathrm{~cm}^{-1}$ and $\mathrm{C}-\mathrm{O}$ stretching of ether group at $1090 \mathrm{~cm}^{-1}$. It should be noted that the $\mathrm{OH}$ peak of rice flour/PVA nanofibers was shifted to a lower wavenumber in comparison with those of the native flour and PVA (Fig. 3c and d). These shifts indicated that new hydrogen bonds generated in the blends became stronger than those of individual polymers. ${ }^{25,26}$ The hydrogen bonds between PVA and rice flour led to enhanced entanglement of biopolymer matrix and consequently increased the fiber processability. However, $\mathrm{OH}$ peak of blend nanofibers at the weight content of rice flour at $37.5 \% \mathrm{w} / \mathrm{w}$ did not change 


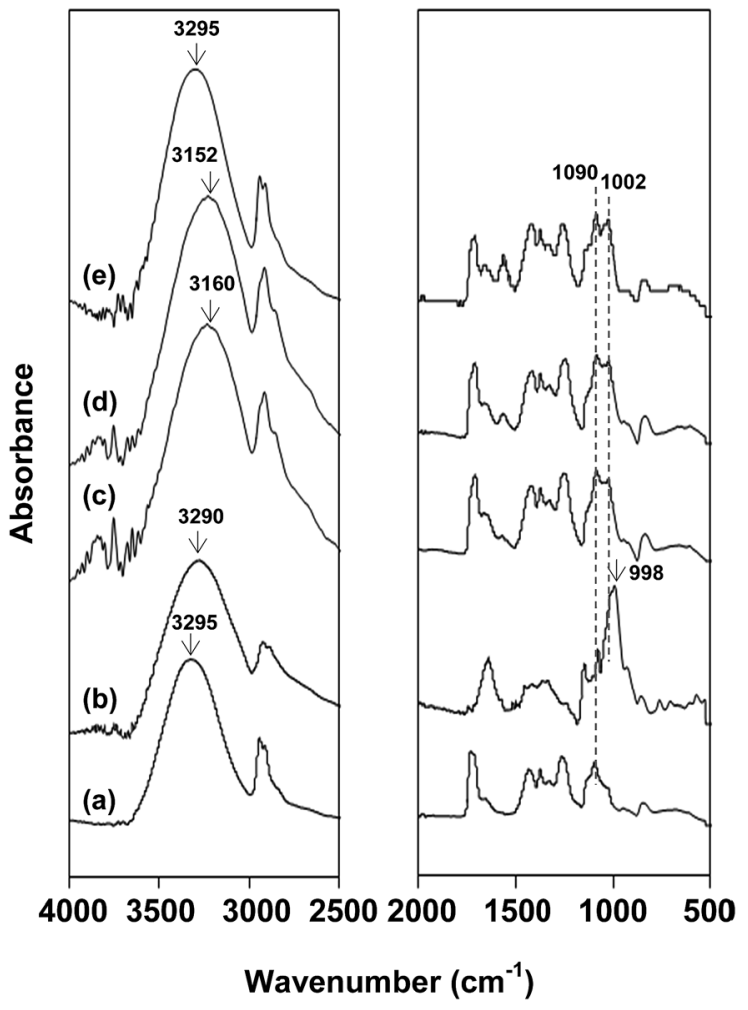

Fig. 3 FTIR spectra of: (a) polyvinyl alcohol (PVA) membrane; (b) rice flour; and (c-e) rice flour/PVA membranes at different contents of rice flour for (c) $12.5 \% \mathrm{w} / \mathrm{w}$, (d) $25 \% \mathrm{w} / \mathrm{w}$ and (e) $37.5 \% \mathrm{w} / \mathrm{w}$.

with respect to that in pure flour due presumably to polymer aggregation (see Fig. 2e).

\subsection{Crystallinity}

XRD technique was employed to analyze the amorphous/ crystalline characteristics of the blend nanofibers in comparison with that of neat substances, i.e. rice flour and PVA nanofibers. Rice flour showed diffraction peaks at $15.2^{\circ}, 17.6^{\circ}, 18.3^{\circ}$ and $23.1^{\circ}$, corresponding to A-type crystal structure,,$^{27,28}$ and PVA nanofibers with a major peak at $19.6^{\circ}$ (Fig. $4 \mathrm{a}$ and b). ${ }^{29}$ Fig. $4 \mathrm{c}-\mathrm{e}$ display XRD patterns of the blend nanofibers with varying rice flour contents. Rice flour/PVA blend nanofibers exhibited similar diffraction peaks at $19.6^{\circ}$ which was attributed to crystalline domain of PVA. However, the diffraction peaks of starch crystal were insignificant, implying destruction of starch granule resulting in homogenous dispersion of rice flour in the blends. When increasing the amount of rice flour used, a small shoulder at $23^{\circ}$ becomes prominent as observed in the blend containing rice flour for $37.5 \% \mathrm{w} / \mathrm{w}$ (Fig. 4e). This might be due to reorganization of rice flour to form imperfect crystal in the fibers after blending and electrospinning. This result agreed with the hypothesis that increased content of rice flour induced aggregation of individual polymer.

The degree of crystallinity and crystallite size of PVA were $35.16 \%$ and $5.40 \mathrm{~nm}$, respectively. Compared with PVA nanofibers, the blend nanofibers at weight content of rice flour of $12.5 \% \mathrm{w} / \mathrm{w}$ and $25 \% \mathrm{w} / \mathrm{w}$ showed higher crystallinity and

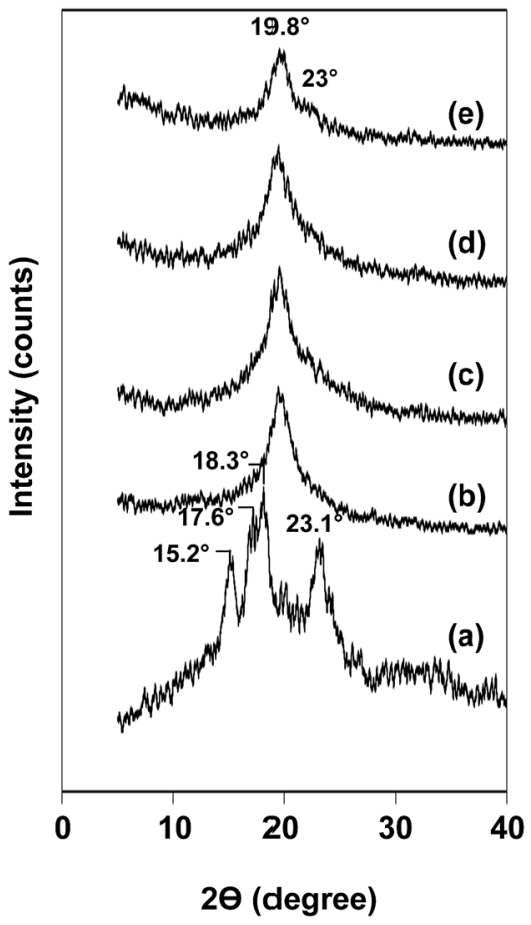

Fig. 4 X-ray diffractograms of (a) rice flour; (b) polyvinyl alcohol (PVA) membrane; and (c-e) rice flour/PVA membranes at different contents of rice flour for (c) $12.5 \% \mathrm{w} / \mathrm{w}$, (d) $25 \% \mathrm{w} / \mathrm{w}$ and (e) $37.5 \% \mathrm{w} / \mathrm{w}$.

smaller crystallite size in the range of $36.6-37.8 \%$ and $4.3-$ $4.6 \mathrm{~nm}$ (Table 1), respectively. This observation was possibly due to starch molecules functioning as a nucleating agent and promoting the crystallization of small PVA crystals. Consistent with our study, Kang et $a l .^{30}$ reported that starch could offer a fully biodegradable nucleating agent with no residues remaining for the biobased and biodegradable polymers. In contrast, crystallinity of the blend nanofibers was decreased at rice flour's content of $37.5 \% \mathrm{w} / \mathrm{w}$, while their crystallite size increased. This might be explained by the aggregation of individual polymer, which then decreased the nucleating sites for the small PVA crystals.

\subsection{Thermal properties}

Thermal properties of rice flour, PVA and rice flour/PVA blend nanofibers were examined by thermogravimetric analysis (TGA) and differential scanning calorimetry (DSC). The temperature for maximum rate of weight loss was determined as decomposition temperature. This could be clearly discerned as a peak in

Table 1 Degree of crystallinity and crystallite size of rice flour/PVA blend nanofibers at different contents of rice flour

\begin{tabular}{lll}
\hline $\begin{array}{l}\text { Solid content of rice } \\
\text { flour in blend nanofibers (\% w/w) }\end{array}$ & $\begin{array}{l}\text { Degree of } \\
\text { crystallinity (\%) }\end{array}$ & $\begin{array}{l}\text { Crystallite } \\
\text { size (nm) }\end{array}$ \\
\hline 0 & 35.16 & 5.40 \\
12.5 & 36.64 & 4.56 \\
25.0 & 37.82 & 4.29 \\
37.5 & 33.84 & 5.82
\end{tabular}


the derivative thermal gravimetric (DTG) thermogram. Fig. 5 showed that the mass loss of rice flour, PVA and rice flour/PVA blend nanofibers progressed as a function of temperature. Rice flour clearly illustrated a two-step mass loss at the temperature range of $47-134{ }^{\circ} \mathrm{C}$ and $284-320{ }^{\circ} \mathrm{C}$, with maximum points at $90{ }^{\circ} \mathrm{C}$ and $300{ }^{\circ} \mathrm{C}$, respectively (Fig. 5Aa and Ba). The former degradation step was attributed to free water evaporation, while the latter epitomized starch decomposition. ${ }^{31}$ PVA exhibited three-step mass losses at temperature ranges of $53-135^{\circ} \mathrm{C}(\max$. at $\left.94{ }^{\circ} \mathrm{C}\right), 276-398{ }^{\circ} \mathrm{C}\left(\max\right.$. at $\left.327{ }^{\circ} \mathrm{C}\right)$ and $414-469{ }^{\circ} \mathrm{C}(\max$ at $447^{\circ} \mathrm{C}$ ) (Fig. $5 \mathrm{Ab}$ and $\mathrm{Bb}$ ). They could be ascribed to evaporation of latent moisture, degradation of side chain $(\mathrm{O}-\mathrm{H})$ and the cleavage of $\mathrm{C}-\mathrm{C}$ backbone of PVA, respectively. ${ }^{32}$ As expected, rice flour/PVA blend nanofibers also possessed three-step mass losses at temperature ranges of $81-93{ }^{\circ} \mathrm{C}, 305-310{ }^{\circ} \mathrm{C}$ and $431-$ $440{ }^{\circ} \mathrm{C}$. The first loss was due to the evaporation of native moisture. The second loss could be from decomposition of PVA's side chain and of glucose units from starch molecule due mainly to broken intra- and intermolecular hydrogen bonds between PVA and starch. The third one was due to degradation of main chain of PVA (Fig. 5Ac-e and Bc-e). ${ }^{15}$ Interestingly, it was noticed that the maximum mass loss temperature of rice flour tended to increase when PVA was added. Previously, Othman et $a l .{ }^{33}$ reported that the thermal decomposition of PVA/starch blends shifted slightly upward with respect to starch owing to enhanced thermal stability induced by the molecular interaction between PVA and starch.

Moreover, DSC was employed as a thermoanalytical technique to unveil glass transition temperature $\left(T_{\mathrm{g}}\right)$, melting temperature $\left(T_{\mathrm{m}}\right)$ and melting enthalpy $\left(\Delta H_{\mathrm{m}}\right)$ of the polymers and blends. Experimentally, the first heating scan was carried out from $-50{ }^{\circ} \mathrm{C}$ to $250{ }^{\circ} \mathrm{C}$, in order to completely erase the

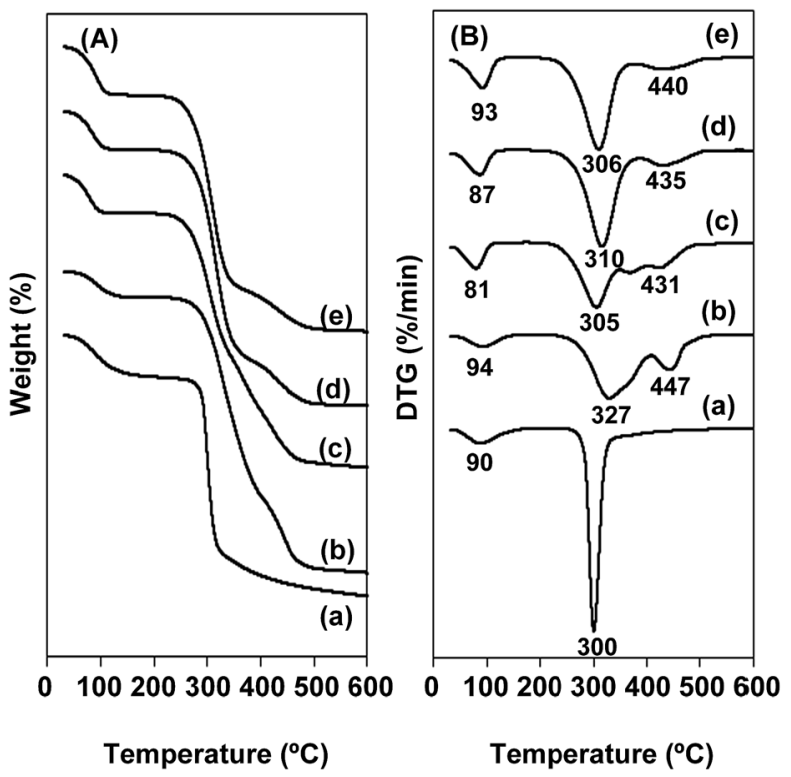

Fig. 5 (A) TGA, (B) DTG thermograms of (a) rice flour; (b) polyvinyl alcohol (PVA) membrane; and (c-e) rice flour/PVA membranes at different contents of rice flour for (c) $12.5 \% \mathrm{w} / \mathrm{w}$, (d) $25 \% \mathrm{w} / \mathrm{w}$ and (e) $37.5 \% \mathrm{w} / \mathrm{w}$. materials' thermal history. Subsequently, the second heating scan was performed as illustrated in Fig. 6. Rice flour did not show any endothermic peak because the starch melting temperature was higher than its decomposition temperature owing to numerous intermolecular hydrogen bonds among the polymer chains. ${ }^{34}$ Consistent with a previous report, PVA exhibited $T_{\mathrm{g}}$ and $T_{\mathrm{m}}$ at $72{ }^{\circ} \mathrm{C}$ and $181{ }^{\circ} \mathrm{C}\left(\Delta H_{\mathrm{m}}=13.35 \mathrm{~J} \mathrm{~g}^{-1}\right)$, respectively. ${ }^{35}$ Rice flour/PVA blend nanofibers gave lower $T_{\mathrm{g}}$ and $T_{\mathrm{m}}$ in the ranges of $65-71{ }^{\circ} \mathrm{C}$ and $168-169{ }^{\circ} \mathrm{C}$, respectively, which were similar to the results reported by Sin et al. (2010). ${ }^{36}$ However, $\Delta H_{\mathrm{m}}$ of blend nanofibers at the weight content of rice flour of $12.5 \% \mathrm{w} / \mathrm{w}$ and $25 \% \mathrm{w} / \mathrm{w}$ was increased (13.38-16.41 J $\mathrm{g}^{-1}$ ) with respect to that of pure PVA. This result was explained by the interaction among the open chain hydroxyl groups of PVA and starch via hydrogen bonding. Another reason could be the nucleating ability of starch that initiated recrystallization of the vinyl polymer. These two physical origins could synergistically constitute towards higher energy of melting as observed previously in literature. ${ }^{37}$ Nevertheless, rice flour/PVA blend nanofibers prepared using rice flour solution of $37.5 \% \mathrm{w} / \mathrm{w}$ possessed lower $\Delta H_{\mathrm{m}}\left(8.75 \mathrm{~J} \mathrm{~g}^{-1}\right)$ than PVA. Since the excess of rice flour might have obstructed the formation of small PVA crystals due to the polymers' aggregation as described above (see Section 3.4.), the apparent reduction of $\Delta H_{\mathrm{m}}$ could be anticipated as the effect from hydrogen bonding was weakened.

\subsection{Mechanical properties}

As demonstrated in Fig. 7, the tensile strength, modulus and elongation at break of the nanofibers could be determined from stress-strain curve. PVA nanofibers showed tensile strength, modulus and elongation at break of 4.60 MPa, 10.44 MPa and $146.40 \%$, respectively (Fig. 7B). Blend nanofibers at the weight content of rice flour of $12.5 \% \mathrm{w} / \mathrm{w}$ and $25 \% \mathrm{w} / \mathrm{w}$ exhibited higher

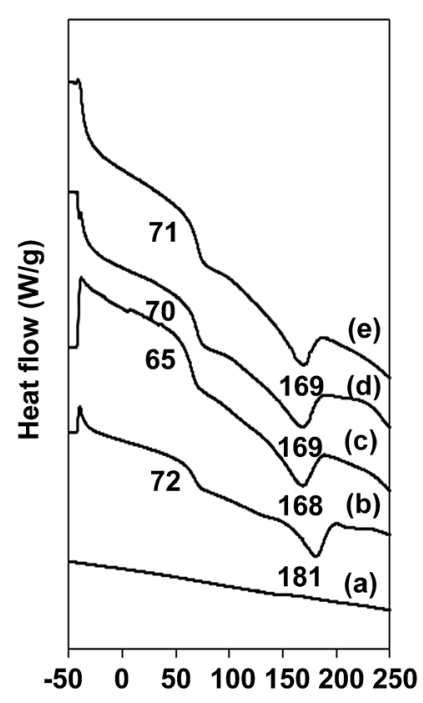

Temperature $\left({ }^{\circ} \mathrm{C}\right)$

Fig. 6 DSC thermograms (exo up) of (a) rice flour; (b) polyvinyl alcohol (PVA) membrane; and (c-e) rice flour/PVA membranes at different contents of rice flour for (c) $12.5 \% \mathrm{w} / \mathrm{w}$, (d) $25 \% \mathrm{w} / \mathrm{w}$ and (e) $37.5 \% \mathrm{w} / \mathrm{w}$. 


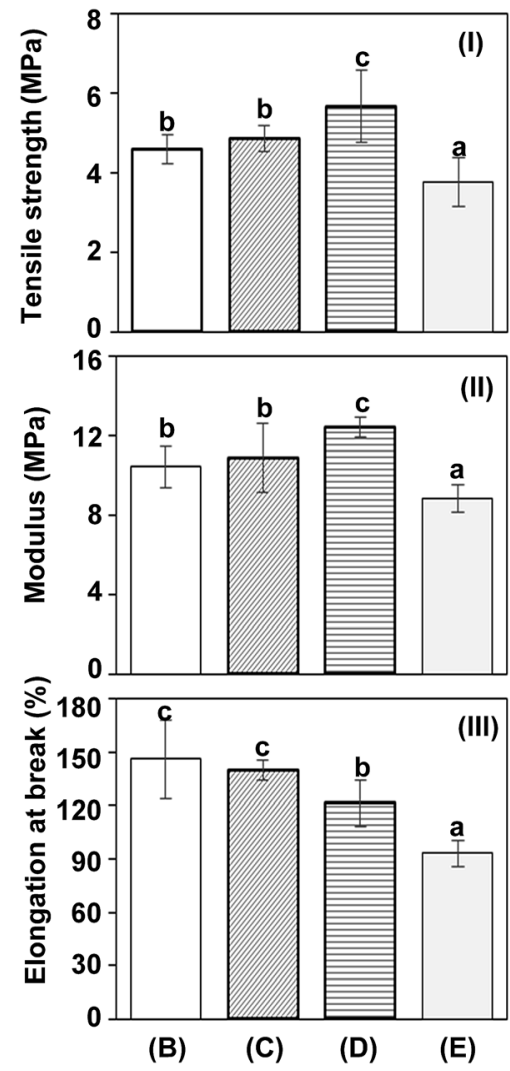

Fig. 7 (I) Tensile strength, (II) modulus and (III) elongation at break of (B) polyvinyl alcohol (PVA) membrane; and (C-E) rice flour/PVA membranes at different contents of rice flour for (C) $12.5 \% \mathrm{w} / \mathrm{w}$, (D) $25 \% \mathrm{w} / \mathrm{w}$ and (E) $37.5 \% \mathrm{w} / \mathrm{w}$. Data are reported as mean $\pm \mathrm{SD}, n=10$. Different superscript letters indicate a significant difference at $p<0.05$ (Duncan's new multiple range test).

tensile strength (4.87-5.67 MPa) and modulus (10.88-12.45 $\mathrm{MPa})$, but lower elongation at break (140.03-121.36\%) than those of the PVA nanofibers. The increase of tensile strength and stiffness, as well as the reduction of extensibility of nanofibers after blending with rice flour might result from the formation of intermolecular bonds between PVA and starch (see Section 3.3.). ${ }^{30}$ However, excess rice flour content $(37.5 \% \mathrm{w} / \mathrm{w})$ led to nanofibrous blend with inferior mechanical properties (tensile strength, modulus and elongation at break of 3.77 MPa, 8.86 MPa and 93.13\%, respectively). This observation was attributed to the formation of intra-molecular hydrogen bonds rather than inter-molecular hydrogen bonds within the asmentioned phase-separated polymer domains. The distinctive discontinuity of the nanofibers (Fig. 2E) could be considered consistent with this rationale. It could be inferred from the above findings that rice flour/PVA nanofibrous membranes could potentially be used as an environmentally disposable and mechanically robust nanofilters.

\section{Conclusions}

Rice flour/PVA blend nanofibers were prepared by electrospinning technique. The contents of rice flour in solution were systematically varied from $0-37.5 \%$, to find that $25 \% \mathrm{w} / \mathrm{w}$ was an optimal condition where good processability, fibers with well-defined morphology and uniform diameter could be successfully achieved. At such condition, (i) viscosity of the blend became 0.40 fold compared to those of PVA and rice flour solutions, (ii) FTIR spectrum revealed the shift of $-\mathrm{OH}$ peak to a lower wavenumber indicating hydrogen bonds between polymer chains and (iii) XRD pattern unveiled an increase in PVA crystallinity at $19.6^{\circ} 2 \theta$. When the two polymers were molecularly stabilized under the above mentioned condition, heat absorption capacity $\left(\Delta H_{\mathrm{m}}\right)$ was increased as the decomposition temperature decreased. Furthermore, the increased tensile strength and Young's modulus as well as reduced elongation were attributed to the intermolecular $\mathrm{H}$ bonding between PVA and rice flour. These findings suggested that rice flour/PVA blend nanofibers could successfully be transformed into biodegradable and mechanically robust nanofibers with potential in various applications such as nanofiltrations.

\section{Acknowledgements}

This work was financially supported by the Agricultural Research Development Agency (Public Organization), Thailand Research Organizations Network and National Research Council of Thailand.

\section{References}

1 P. Yang and P. A. Seib, Cereal Chem., 1996, 73, 751-755.

2 S. Puncha-arnon and D. Uttapap, Carbohydr. Polym., 2013, 91, 85-91.

3 W. Zou, L. Yu, X. Liu, L. Chen, X. Zhang, D. Qiao and R. Zhang, Carbohydr. Polym., 2012, 87, 1583-1588.

4 K. Leja and G. Lewandowicz, Pol. J. Environ. Stud., 2010, 19, 255-266.

5 U. Shah, F. Naqash, A. Gani and F. A. Masoodi, Compr. Rev. Food Sci. Food Saf., 2016, 15, 568-580.

6 S. F. Dehghan, F. Golbabaei, B. Maddah, R. Yarahmadi and A. S. Zadeh, Int. J. Occup. Hyg., 2015, 7, 110-118.

7 J. Fan, Y. Cao, T. Li, J. Li, X. Qian and J. Shen, ACS Sustainable Chem. Eng., 2015, 3, 1866-1872.

8 Z. M. Huang, Y. Z. Zhang, M. Kotaki and S. Ramakrishna, Compos. Sci. Technol., 2003, 63, 2223-2253.

9 T. Ondarcuhu and C. Joachim, Europhys. Lett., 1998, 42, 215220.

10 G. Liu, J. Ding, L. Qiao, A. Guo, B. P. Dymov, J. T. Gleeson, T. Hashimoto and K. Saijo, Chem.-Eur. J., 1999, 5, 27402749.

11 C. R. Martin, Chem. Mater., 1996, 8, 1739-1746.

12 J. M. Deitzel, J. D. Kleinmeyer, J. K. Hirvonen and N. C. Beck Tan, Polymer, 2001, 42, 8163-8170.

13 L. Kong and G. R. Ziegler, Carbohydr. Polym., 2013, 92, 14161422.

14 P. Jaiturong, K. Sutjarittangtham, S. Eitsayeam and J. Sirithunyalug, Adv. Mater. Res., 2012, 506, 230-233. 
15 E. Negim, R. Rakhmetullayeva, G. Yeligbayeva, P. Urkimbaeva, S. Primzharova, D. Kaldybekov, J. Khatib, G. Mun and W. Craig, Int. J. Basic Appl. Sci., 2014, 3, 263-273.

16 C. A. Rodrigues, A. Tofanello, I. L. Nantes and D. S. Rosa, ACS Sustainable Chem. Eng., 2015, 3, 2756-2766.

17 I. Vroman and L. Tighzert, Materials, 2009, 2, 307-344.

18 J. C. Park, T. Ito, K. O. Kim, K. W. Kim, B. S. Kim, M. S. Khil, H. W. Kim and I. S. Kim, Polym. J., 2010, 42, 273-276.

19 J. I. Langford and A. J. C. Wilson, J. Appl. Crystallogr., 1978, 11, 102-113.

20 A. B. Norton, R. D. Hancocks and L. M. Grover, Food Hydrocolloids, 2014, 42, 373-377.

21 Z. Liu and J. H. He, Therm. Sci., 2014, 18, 1473-1475.

22 Z. Khatri, S. Ali, I. Khatri, G. Mayakrishnan, S. H. Kim and I. S. Kim, Appl. Surf. Sci., 2015, 342, 64-68.

23 M. Ahmad, N. M. Hani, N. P. Nirmal, F. F. Fazial, N. F. Mohtar and S. R. Romli, Prog. Org. Coat., 2015, 84, 115-127.

24 M. G. Lomelí-Ramírez, A. J. Barrios-Guzmán, S. GarcíaEnriquez, J. D. J. Rivera-Prado and R. Manríquez-González, BioResources, 2014, 9, 2960-2974.

25 K. J. Eichhorn, A. Fahmi, G. Adam and M. Stamm, J. Mol. Struct., 2003, 661-662, 161-170.

26 A. Watanabe, S. Morita and Y. Ozaki, Biomacromolecules, 2007, 8, 2969-2975.
27 R. Hoover, Carbohydr. Polym., 2001, 45, 253-267.

28 C. Yokesahachart and R. Yoksan, Carbohydr. Polym., 2011, 83, 22-31.

29 A. Pangon, S. Saesoo, N. Saengkrit, U. Ruktanonchai and V. Intasanta, Carbohydr. Polym., 2016, 138, 156-165.

30 K. S. Kang, S. I. Lee, T. J. Lee, R. Narayan and B. Y. Shin, Korean J. Chem. Eng., 2008, 25, 599-608.

31 C. Y. Teh, T. Y. Wu and J. C. Juan, Ecol. Eng., 2014, 71, 509519.

32 N. Ahad, E. Saion and E. Gharibshahi, J. Nanomater., 2012, 2012, 1-8.

33 N. Othman, N. A. Azahari and H. Ismail, Malaysian Polymer Journal, 2011, 6, 147-154.

34 S. Thomas, D. Durand, C. Chassenieux and P. Jyotishkuma, in Handbook of biopolymer-based materials: from blends and composites to gels and complex networks, ed. V. Samouillan, J. Dandurand and C. Lacabanne, Wiley, New York, 2013, vol. 2, ch. 8, pp. 371-401.

35 Y. T. Jia, J. Gong, X. H. Gu, H. Y. Kim, J. Dong and X. Y. Shen, Carbohydr. Polym., 2007, 67, 403-409.

36 L. T. Sin, W. A. W. A. Rahman, A. R. Rahmat and M. I. Khan, Carbohydr. Polym., 2010, 79, 224-226.

37 P. Chopra, S. Garg and A. K. Jana, Int. J. Res. Mech. Eng. Tech., 2013, 3, 36-40. 